\title{
Problems and Improvement Measures in Mechanical Principle Course Teaching for the Non-Mechanical Majors
}

\author{
Yong Yang ${ }^{1, a^{*}, \text { Zi-yang Cao }}{ }^{2, b}$ and Li-hua Guo ${ }^{3, c}$ \\ ${ }^{1}$.College of Mech. Eng., Suzhou Univ. of Science and Tech., Suzhou 215009, China; \\ ${ }^{2}$ Key Laboratory for Precision and Efficient Processing Tech., Suzhou Univ. of Science and Tech., \\ Suzhou 215009, China; \\ a yangyong5114360@163.com, bdukeczy@nuaa.edu.cn, clihuaguo2008@163.com
}

Keywords: Mechanical principle; Non-mechanical major; Teaching improvement

\begin{abstract}
The characteristics of mechanical principles course teaching for non-mechanical majors are analyzed. The existing problems in mechanical principle teaching for non-mechanical majors are put forward. On these bases, aiming at these problems, the improvement measures of mechanical principles course teaching oriented to non-mechanical majors are proposed. It is proved by practices that: the proposed teaching improvement measures have a good effect on enhancing the mechanical principles teaching for non-mechanical majors.
\end{abstract}

\section{Introduction}

The course of mechanical principle takes the machinery (the generic terms of mechanism and machine) as the study objectives, and research the structure, quality, force and also movement of machinery. It mainly includes two parts: the kinematic of machinery and the dynamics of machinery [1-2].

The course of mechanical principle is not only a key professional basic course for mechanical majors, but also a professional basic course for non-mechanical majors or majors similar to the mechanics major. This course has the characteristics such as the wide content, the strong practicality and applicability, and so on. The students in non-mechanics majors are poor in the related mechanical knowledge, engineering practice and also the mechanical perception [3-4].

In some cases, the way of thinking of students established through their professional learning is quite different from that of mechanical majors evenly. Therefore, in the course teaching of mechanical principle for non-mechanic majors, it is necessary to combine the contents of the teaching materials with the characteristics of students in non-mechanical majors, so as to improve the teaching quality of the course of mechanical principle. [5-6].

\section{Analysis on Teaching Characteristics of Mechanical Principle for Non-mechanic Majors}

Supporting Effect of Mechanical Principles for Other Professional Courses. As one basic mechanical course, for the students in non-mechanical majors, the course of mechanical principle can establish the foundation for learning related knowledge about mechanical structure and other aspects. The purpose of learning this course is to better understand the basic mechanical knowledge and theory in their majors.

Teaching of Mechanical Principles has the Requirement of Professional Characteristics. The purpose of learning mechanical principles in non-mechanical majors is to better understand the mechanical basic knowledge related to these majors, so the teaching of mechanical principles for non-mechanical major needs to reflect the major characteristics. And also through the general principles and methods, the professional characteristic machineries can be analyzed and researched.

Targeted Requirements of Mechanical Principles for Teaching Content is Stronger. The mechanical principles learning for the students in mechanic major are more comprehensive and widely. But the situation is different in the non-mechanic major, the students in non-mechanic majors can choose pertinent contents according to their professional needs. For example, the derivation of related 
formulas in mechanical theory teaching is tedious and lengthy. But for non-mechanical majors, more emphasis should be placed on the application of theoretical methods.

\section{Problems in the Teaching of Mechanical Principle for Non-mechanic Majors}

Teachers' Problems in the Teaching of Mechanical Principles for Non-mechanical Majors. The teaching staff of mechanical principles course for non-mechanical majors are often from other college, and they don't know these non-mechanical majors well. The depth and breadth of mechanical principles controlled by teachers reasonably, and the combination between curriculum contents and professional characteristics effectively become the big problems.

Under these circumstances, the instructors select teaching contents, teaching methods and teaching examples according to their understanding about these non-mechanical majors. Obviously, these would affect the quality and effect of mechanical principles teaching greatly. Therefore, the familiarity about non mechanical majors of the teachers would have the very important impact on their teaching.

Problem of Teaching Object in Mechanical Principle Teaching for Non-mechanical Majors. Before the course of mechanical principle, students need to grasp the base knowledge about mechanics, materials, engineering drawing and so on, and have the certain mechanical perceptual knowledge and space imagination. The students in non-mechanical majors don't study the engineering drafting, theoretical mechanics, material mechanics and other courses systematically before this course, and lack in the coherence of relevant basic knowledge.

Moreover, in some cases, the thinking mode trained by professional learning is quite different from that of mechanical students. All these make it difficult for the students in non-mechanical majors to learn mechanical principles. In addition, the non-mechanical students have no complete perception about mechanical discipline, and aren't aware of the important role that the teaching content of the mechanical principle course in their own majors. Therefore, students are less concerned about this course, and their interest in learning is not high and the enthusiasm is rather poor.

Matching Deviation between Teaching Content and Knowledge Structure of Non-mechanical Students. The course of mechanical theory is rich in content, and requires strong professional foundation. The principles, methods and mathematical knowledge used are quite complex. In the teaching course for non-mechanical majors, some teachers carry out the detailed and tedious deduction to the whole formula, so as to explain some formulas and principles. And the examples used are completely irrelevant to these majors. So the students are very difficult to understand.

While some teachers only introduce the surface phenomenon of the related process, and simplify the teaching content excessively. Both these ways can't match with the knowledge structure of non-mechanical students, which seriously affects the teaching effect.

Connection Problem between Mechanical Principles and other Basic Courses. An important purpose for non-mechanical majors to learn machine principles is to lay a solid foundation for further learning of other basic courses. In the course teaching of mechanical principle for non-mechanical students, the more emphasis about systematicness are placed on this course, but the connection with other basic courses is ignored.

This so-called curriculum integrity undermines the systematicness and comprehensiveness of professional learning in this major. Due to the lack of cohesion between mechanical principles and other basic courses, subsequent professional basic courses are still isolated. More emphasis is placed on imparting the knowledge in the course of teaching, but the lack of connection with the basic courses characteristics makes it difficult for students to understand the direct relationship between mechanical principles and their own majors.

\section{Improvement Measures of Mechanical Principle Teaching for Non-mechanical Major}

Teachers should Reinforce the Related Knowledge and Application Examples about the Teaching Major. It is very necessary to enhance the teachers' understanding of the role of this course and also the related knowledge in their teaching major, which is the primary measure to improve mechanical 
principle teaching quality in non-mechanic major. Before teaching this course for non-mechanical major, the teachers should firstly know this major well, and have gained some understanding about the content of mechanical principle which may be used by the typical machine with professional characteristics in this major.

According to the role of mechanical principle in this major, teachers should combine the content of this course with this major, and give the relative teaching examples with professional characteristics, so as to make the students understand the teaching contents and methods of this course more easily on the basis of certain relevant knowledge of this major.

Strengthen the Learning of Related Basic Mechanical Knowledge for Non-mechanical Students. The non-mechanic students are poor in theoretical mechanics, material mechanics, engineering mechanics and other basic courses before learning mechanical principles. Therefore, the instructors need to impart the relevant knowledge to the students in the teaching as the supplement, and pay attention to strengthen the related basic theory of mechanical for students in this major.

For example, in the speed analysis of mechanism based on the instantaneous center method, the instructors firstly need to introduce the basic knowledge of the absolute instantaneous center, the relative instantaneous center, theorem of three centers and so on, so as to make the students understand how to analyze the speed by the instantaneous center method well, and improve the study interests of students.

Combination between Teaching for Targeted Professional Needs and Teaching with Professional Characteristics Examples. Teaching oriented to major demand: according to the major requirements, combining with the actual characteristics of the students, the teaching content can be adjusted, and also the key and difficult points can be changed. For example in the industrial design major, teachers can explain more about the mechanisms design, the composition and evolution of the mechanisms, but can give up or simply introduce the balance of the rigid rotor.

Teaching with professional characteristics examples: in the teaching process, it is necessary to explain the principles and methods with the professional characteristics examples, which can make students to resonate and have interests easier. For example, for the students in the major- Heating, Ventilating and Air Conditioning, the calculation of freedom degree can be reached with the wind guiding mechanism in the air conditioner, which is closer to their major.

Pay more Attention to Connection between Mechanical Principles and other Basic Courses. From the systematic perspective of professional disciplines, pay more attention to the connection between mechanical principles and other professional basic courses, and also the serve role of mechanical principles for the following professional courses, instead of emphasizing the integrity of the mechanical principles course only.

More examples related to the follow-up professional basic courses can be introduced. So the students can understand the direct relationship between mechanical principle learning and their own majors, and also know how to creatively solve practical problems related to their major with mechanical principles.

\section{Practical Effect of Teaching Improvement Measures}

Proposed teaching improvement measures of mechanical principles for non-mechanical majors have been implemented in the major of building environment and energy application engineering. From the perspective of teaching effect, students generally reflect that the learning contents of mechanical principles are easier to understand. Students' interest in learning has been greatly improved, and the importance of this course to their majors has been recognized. Students can effectively integrate their knowledge with their professional problems, and creatively solve the professional problem.

\section{Conclusions}

The problems in the mechanical principles teaching for non- mechanic specialties are put forward: teachers' problems in the teaching of mechanical principles for non-mechanical majors; problem of teaching object in mechanical principle teaching for non-mechanical majors; matching deviation between teaching content and knowledge structure of non-mechanical students, and so on. 
Aim at these problems, the improvement measures for the mechanical principles teaching for non-mechanical majors are proposed: enhance the teachers to learn the related knowledge and practical examples of the non-mechanic majors; strengthen the learning of related basic mechanical knowledge for non-mechanical students; pay more attention to connection between mechanical principles and other basic courses, and so on.

The proposed teaching improvement measures of mechanical principles for non-mechanical majors have been implemented in the major of building environment and energy application engineering. It is proved that: the proposed teaching improvement measures have a good effect on the mechanical principles teaching for non-mechanical major.

\section{Acknowledgements}

This research is funded by a high level demonstration project of Sino foreign cooperative education in Jiangsu Province - undergraduate education project of mechanical design, manufacturing and automation.

\section{References}

[1] H. Sun and Z. M. Chen: Mechanical Principle (Eighth Edition) (Higher Education Press, Beijing 2013).

[2] L. N. Robert: Design of Machinery (Third Edition) (Higher Education Press, Beijing 2007).

[3] J. Hua, C. X. Zhou and X. M. Yuan: Teaching research on mechanical principles with petroleum industry characteristics, Education Times, 2011 (6): 3-3.

[4] X. Li: Innovative research on the teaching of mechanical principles and design courses for communication majors, Digital Communication World, 2016 (3): 299-299.

[5] B. Jiang: Teaching reformation and practice on mechanical principle course in civilian-run colleges, International Conference on Education, Management, Computer and Medicine (Shenyang, China, April 24-26, 2016).

[6] Y. Yang, J. L. Jiang and D. X. Wang: Construction of innovative teaching system and mode for mechanical principle course facing ability target of international engineering education, International Conference on Modern Management, Education Technology, and Social Science (Sanya, China, Nov 19-20, 2017). 